\title{
Hospitalizations of cancer patients in the last month of life: quality indicator scores reveal large variation between four European countries in a mortality follow-back study
}

Maaike L De Roo ${ }^{1 *}$, Anneke L Francke ${ }^{1,2}$, Lieve Van den Block ${ }^{3}$ Gé A Donker², Jose E Lozano Alonso ${ }^{4}$, Guido Miccinesi ${ }^{5}$, Sarah Moreels ${ }^{6}$, Bregje D Onwuteaka-Philipsen ${ }^{1}$, Andrea Salvetti ${ }^{7}$, Luc Deliens ${ }^{1,3}$, on behalf of EURO IMPACT

\begin{abstract}
Background: Repeated and long hospitalizations of cancer patients at the end of life have been suggested as indicators of low quality of palliative care. Comparing the care delivered between different countries with the help of these quality indicators may identify opportunities to improve practice. Our objective is twofold: firstly, to describe the scores for the existing quality indicators "the percentage of time spent in hospital" and "the proportion of adult patients with more than one hospitalization in the last 30 days of life" in populations of cancer patients in four European countries and to see whether these countries met previously defined performance standards; secondly, to assess whether these scores are related to receiving palliative care from their GP.

Methods: A mortality follow-back study was conducted, based on data recorded by representative GP networks for samples of cancer patients living at home who died non-suddenly in Belgium $(n=500)$, the Netherlands $(n=310)$, Italy $(n=764)$, and Spain $(n=224)$.

Results: The quality indicator score for "the percentage of time spent in hospital" in the last month of life was $14.1 \%$ in the Netherlands, $17.7 \%$ in Spain, $22.2 \%$ in Italy, and 24.6\% in Belgium, which means that none of the countries met the performance standard of $<10 \%$. For the "proportion of patients with more than one hospitalization in the last 30 days of life", two countries met the performance standard of <4\%: the Netherlands $(0.6 \%)$ and Italy (3.1\%). Spain had a score of $4.0 \%$ and Belgium scored $5.4 \%$. When patients received palliative care from their GP, significantly less time was spent in hospital in the last month and fewer hospitalizations took place.

Conclusions: European countries differ regarding the frequency and duration of hospitalizations of cancer patients in the last month of life. This reflects country-specific differences in the organization of palliative care and highlights the important role of the GP in palliative care provision.
\end{abstract}

Keywords: Hospitalizations, Palliative care, Quality indicators

\footnotetext{
* Correspondence: eol@vumc.nl

'VU University Medical Center, EMGO Institute for Health and Care Research, Department of Public and Occupational Health, Expertise Center of Palliative Care, Van der Boechorststraat 7, 1081 BT Amsterdam, the Netherlands

Full list of author information is available at the end of the article
} 


\section{Background}

High rates of hospitalization at the end of life may be an indication that palliative care is of suboptimal quality, since these hospitalizations can be associated with offering aggressive and futile treatments [1,2], with too much focus on life prolongation rather than the patient's quality of life and the relief of symptom burden, with inadequate communication about the patient's care preferences or with the limited availability or use of palliative home-care services [3]. Although some hospitalizations may be inevitable $[4,5]$, there may be potential to reduce the number and duration of hospitalizations [6], e.g. by providing appropriate support from general practitioners $[1,7]$.

Long or repeated hospital admissions at the end of life have been suggested as indicators that palliative care is of a poor quality $[1,8,9]$. Several quality indicators for palliative care concerning the frequency and duration of hospitalizations at the end of life have already been developed [1,9-12]. Measuring these quality indicators can give insights into areas where the quality of care is not optimal, subsequently enabling priorities to be set for quality improvement [12]. In this study, we used two quality indicators regarding hospitalizations, selected specifically because they could be derived from the existing data records of general practitioners (GPs) in Belgium, the Netherlands, Italy, and Spain. The first is "the percentage of time spent in hospital", coming from a set of quality indicators developed in Italy for palliative home care [9]. The second quality indicator used concerns "the proportion with more than one hospitalization in the last 30 days of life". This quality indicator is part of an indicator set that was developed in the United States for cancer patients $[1,10,11]$. These indicators have specific performance standards: namely that less than $4 \%$ of cancer patients should have more than one hospitalization in the last month of life [10] and that less than $10 \%$ of time should be spent in hospital [9]. Using these existing indicators, instead of constantly developing new indicators for palliative care offers advantages. In this case, deriving these indicators from data collected by existing registrations by GPs, we further tested the usefulness of these indicators in international comparative research.

Comparing the care delivered between different countries may help identify opportunities to improve practice [13], particularly when the comparison includes an investigation of the factors that are associated with poor or better quality indicator scores. In this paper, we therefore also look at whether there is a relationship with the delivery of palliative care by GPs. Previous studies have shown that the provision of palliative care by GPs is associated with less time spent in hospital and fewer hospitalizations $[4,5]$. It is also important to examine whether there is a relationship with GP provision of palliative care because the roles of GPs differ between countries. In some countries, like the Netherlands and Spain, GPs function as gatekeepers [14] to hospital care: except in very acute situations, patients need a formal referral from the GP to see a medical specialist in a hospital. Hence, this provides an opportunity for preventing avoidable hospitalizations. Although GPs in Belgium and Italy do not have this strict gatekeeper function, they are still central professionals in the healthcare system and have a coordinating role, since most people have their "own" GP whom they consult when they have medical problems [15]. Another aspect of the GP's function that differs between countries is their role in the provision of palliative care. In the Netherlands, the GP plays a central role in the delivery of generalist palliative care at home [16-18]. In the other three countries, the GP shares the responsibility of palliative care delivery with generalist or specialist palliative-care home teams [14,15,18-20].

This paper addresses the following research questions:

1) What is a) the percentage of time spent in hospital in the last month of life, and b) the proportion of cancer patients with more than one hospitalization in the last 30 days of life who lived at home and who died non-suddenly in Belgium, the Netherlands, Italy, or Spain?

2) Do the countries meet the performance standards defined for these two quality indicators?

3) Do these quality indicator scores differ between the cancer patients who received palliative care from their general practitioner and those who did not receive palliative care from their GP?

\section{Methods}

\section{Study design}

This paper is based on data from the European Sentinel GP Networks Monitoring End-of-Life Care (EURO SENTI-MELC) study, a mortality follow-back study on monitoring end-of-life care in Belgium, the Netherlands, Spain, and Italy. For this study, we used data from the nationally representative GP networks [14] collected in 2009 (all countries except Spain), 2010 (all four countries) and 2011 (Spain only). The GP sentinel networks cover $1.8 \%$ and $0.8 \%$ of the Belgian and Dutch national populations respectively $[14,21,22]$. In Spain, the two sentinel networks involved in this study account for $3.5 \%$ of the patient population in the Castilla y León region (in the northwest) and $2.2 \%$ in the Comunitat Valenciana region (in the east) $[14,23]$. The Italian data came from a new GP network set up for this study [24] and were collected from nine of the 146 health districts, covering about $4 \%$ of the national patient population [14]. The participating GPs in all four countries were representative for the general population of GPs in each 
country (or health districts in Italy and regions in Spain) in terms of age, gender, and geographical distribution $[14,25,26]$.

\section{Study population}

Since one of the two quality indicators selected was developed for a cancer population and the other for a population receiving home care, we decided to focus on a population of cancer patients who lived at home in the last month of life. The data were analyzed of deceased adult cancer patients (aged 18 and above), who had died non-suddenly according to their GP. Since this study examines the care delivered at the end of life, the data of people who died suddenly and unexpectedly according to their GP were excluded, leaving a population that was eligible for palliative care [21].

\section{Data collection}

In the EURO SENTI-MELC study, GPs recorded the characteristics of recently deceased patients on a weekly basis using a standardized questionnaire. Recall bias was minimized by requiring data entry to be no more than one week after the GP had been informed of the patient's death [14]. In the questionnaire, GPs were asked about the place of death and place(s) of residence in the last three months before death, as well as the length of stay in specific care settings in the last 30 days before death. Thus, the number of hospitalizations and the length of stay in hospital in the last month of life could be deduced. GPs were asked to indicate whether they provided palliative care by the following question: "Did you provide palliative care to this patient?" ["no"; "yes, but not until death"; "yes, until death" (dichotomized into "yes" and "no")].

\section{Informed consent and patient anonymity}

After being informed of the objectives and procedures of the study, participating GPs gave written informed consent at the beginning of each registration year. Strict procedures regarding patient anonymity were employed during data collection and entry; every patient was assigned an anonymous reference code by their GP and any identifying patient and GP data (such as date of birth, postcode, and GP identification number) were replaced with aggregate categories or anonymous codes.

\section{Ethical approval}

The protocol of this study was approved by the Ethical Review Board of Brussels University Hospital of the Vrije Universiteit Brussel (2004), Belgium, and the Local Ethical Committee, 'Comitato Etico della Azienda U.S.L. n. 9 di Grosseto' (2008), Tuscany, Italy. In the Netherlands and Spain, no ethical approval is required for the posthumous collection of anonymous patient data.

\section{Statistical analysis}

The quality indicator "the percentage of time spent in hospital" is calculated using "number of days in hospital during home palliative care" as the numerator and "the total number of days of home palliative care" as the denominator. The performance standard "less than $10 \%$ of time should be spent in hospital" [9] was originally specified for patients who received home palliative care. In this study, it is calculated for the last month of life, for cancer patients regardless of whether they received home palliative care. The second quality indicator, "the proportion with more than one hospitalization in the last 30 days of life", was calculated using "the number of patients who died from cancer and had more than one hospitalization in the last 30 days of life" as the numerator and "the number of patients who died from cancer" as the denominator. We used the original performance standard: "less than $4 \%$ of cancer patients should have more than one hospitalization in the last month of life" [10].

To enable a valid comparison between countries, the quality indicator scores were standardized for patients' gender, age at death, and cancer type, using the distribution observed in the study population as a whole as the reference distribution.

To test whether these quality indicator scores differed significantly between the patients who received palliative care from their GP and those who did not, we used a Mann Whitney U test for "the percentage of time spent in hospital" and a Fisher's Exact test for "the proportion with more than one hospitalization in the last 30 days of life". Standardization of the quality indicator scores to enable valid comparison between the two groups was not applied, since the two groups did not differ significantly in terms of gender, age at death, and cancer type. The analyses were performed using IBM SPSS Statistics software, Version 20.0 (IBM Corp., 2011, Armonk, NY), with significance level $\alpha<0.05$.

\section{Results}

\section{Description of the sample}

The total sample in this study consisted of 1798 patients: 500 for Belgium, 310 for the Netherlands, 764 for Italy and 224 for Spain (see Figure 1). In all countries, the majority of the patients in the samples were male. About one fifth of the Italian and Spanish samples were aged 85 or older, whereas this group of the very elderly was smaller in Belgium (13.9\%) and the Netherlands (11.3\%) (Table 1). Lung cancer and colorectal cancer were the most common types of cancer in all four countries (Table 1). The proportion of cancer patients in each country receiving palliative care from their GP ranged from $61.4 \%$ (Belgium) to $73.9 \%$ (the Netherlands) (Table 1).

Overall, GPs knew where the patient was residing in the last 30 days of life in $96 \%$ of the cases. The 


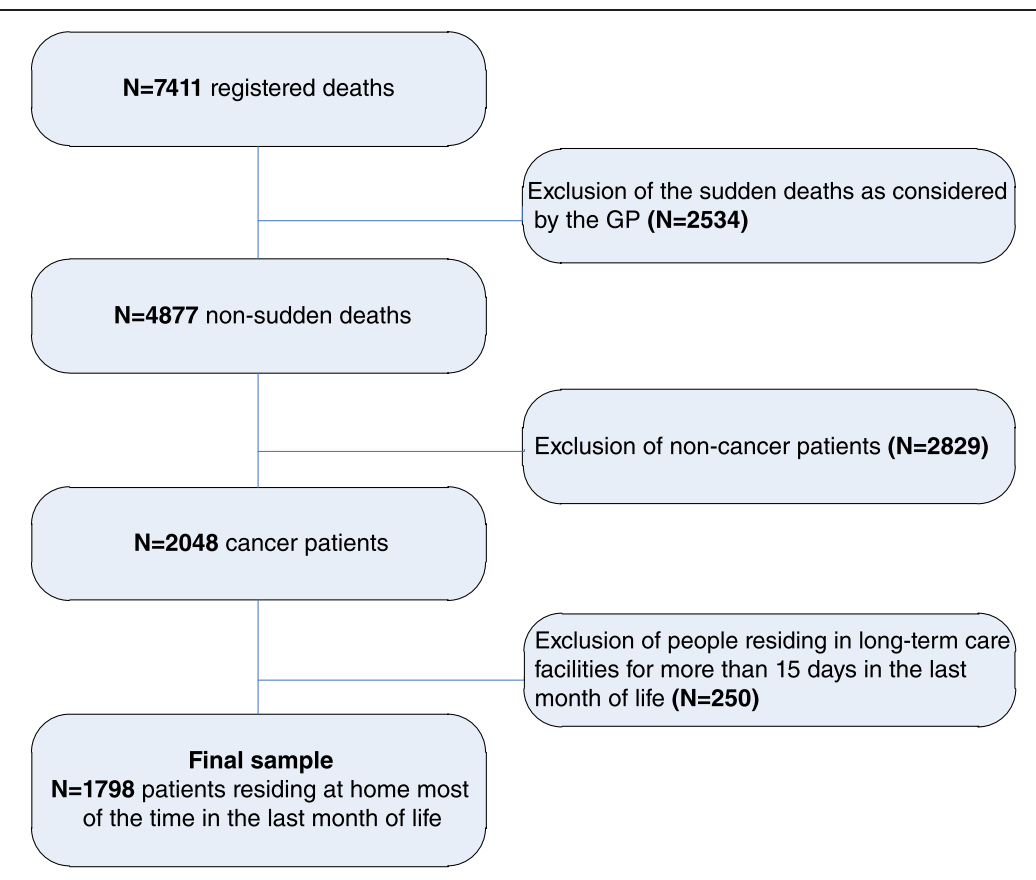

Figure 1 Flowchart of the sample selection.

Table 1 Characteristics of study population per country $(\mathrm{N}=1798)$

\begin{tabular}{|c|c|c|c|c|}
\hline & $\begin{array}{c}\text { Belgium } \\
(\mathrm{N}=500) \\
\mathrm{N}(\%)\end{array}$ & $\begin{array}{l}\text { The Netherlands } \\
(\mathrm{N}=310) \\
\mathrm{N}(\%)\end{array}$ & $\begin{array}{c}\text { Italy } \\
(\mathrm{N}=764) \\
\mathrm{N}(\%)\end{array}$ & $\begin{array}{c}\text { Spain } \\
(\mathrm{N}=224) \\
\mathrm{N}(\%)\end{array}$ \\
\hline \multicolumn{5}{|l|}{ Gender* } \\
\hline Female & $210(42.0)$ & $138(44.8)$ & $344(45.0)$ & $69(31.1)$ \\
\hline Male & $290(58.0)$ & $170(55.2)$ & $420(55.0)$ & $153(68.9)$ \\
\hline \multicolumn{5}{|l|}{ Age at death ${ }^{\dagger}$} \\
\hline $18-64$ years & $150(30.3)$ & $88(28.4)$ & $180(23.6)$ & $51(22.8)$ \\
\hline $65-84$ years & $276(55.8)$ & $187(60.3)$ & $430(56.3)$ & $132(58.9)$ \\
\hline 85 years and older & 69 (13.9) & $35(11.3)$ & $154(20.2)$ & $41(18.3)$ \\
\hline \multicolumn{5}{|l|}{ Cancer type ${ }^{\ddagger}$} \\
\hline Lung cancer & $135(27.0)$ & $78(26.4)$ & $174(27.6)$ & $44(20.2)$ \\
\hline Breast cancer & $39(7.8)$ & $30(10.2)$ & $51(8.1)$ & $11(5.0)$ \\
\hline Colorectal cancer & $59(11.8)$ & $34(11.5)$ & $92(14.6)$ & $42(19.3)$ \\
\hline Prostate cancer & $20(4.0)$ & $22(7.5)$ & $30(4.8)$ & $22(10.1)$ \\
\hline Other & $247(49.4)$ & $131(44.4)$ & $283(44.9)$ & $99(45.4)$ \\
\hline \multicolumn{5}{|c|}{ GP provided palliative care ${ }^{\S}$} \\
\hline No & $193(38.6)$ & $79(26.1)$ & $277(36.3)$ & $62(28.8)$ \\
\hline Yes & $307(61.4)$ & $224(73.9)$ & $486(63.7)$ & $153(71.2)$ \\
\hline
\end{tabular}

*Missing values: Belgium no missing values, the Netherlands $\mathrm{N}=2$, Italy no missing values, $\mathrm{Spain} \mathrm{N}=2$.

${ }^{+}$Missing values: Belgium $\mathrm{N}=5$, the Netherlands, Italy and Spain no missing values.

${ }^{\ddagger}$ Missing values: Belgium no missing values, the Netherlands $N=15$, Italy $N=134$, Spain $N=6$.

${ }^{\S}$ Missing values: Belgium no missing values, the Netherlands $\mathrm{N}=7$, Italy $\mathrm{N}=1$, Spain $\mathrm{N}=9$. 
percentage of GPs who did not know where the patient resided was lowest in the Netherlands (1\%), and highest in Spain (14\%). GPs in Belgium and Italy did not know where the patient resided in the last month of life for $3 \%$ of their patients (not shown in Tables).

Quality indicator "the percentage of time spent in hospital" The Netherlands had the lowest percentage of time spent in hospital in the last month of life (14.1\%), and Belgium the highest percentage (24.6\%) (Table 2). If we compare quality indicator scores between the cancer patient group who did receive GP palliative care and the group who did not, we see that in all countries the quality indicator scores are significantly lower, i.e. less time was spent in hospital, for the group that received GP palliative care (Table 2). Only the group of cancer patients who received palliative care from their GP in the Netherlands met the performance standard of $10 \%$, as they spent only $7.5 \%$ of their last month in hospital.

\section{Quality indicator "the proportion with more than one hospitalization in the last $\mathbf{3 0}$ days of life"}

The Netherlands had the lowest proportion with more than one hospitalization in the final month of life $(0.6 \%)$, followed by Italy (3.1\%). Spain (4.0\%) and Belgium (5.4\%) had a higher proportion of multiple hospitalizations (Table 2). The performance standard of less than $4 \%$ was thus met in two countries: the Netherlands and Italy (Table 2).

There were fewer rehospitalizations among the group of cancer patients who received GP palliative care, although a significant difference was only found in Italy (Table 2). The performance standard of 4\% was met for the patients receiving GP palliative care in three countries: the Netherlands (0.4\%), Italy (2.1\%), and Spain (3.3\%). The Belgian score of $4.2 \%$ almost met the performance standard. In the Netherlands, the performance standard was also met for the group of patients who did not receive palliative care from their GP (Table 2).

\section{Discussion}

The percentage of time spent in hospital during the last month of life varied between the four countries, ranging from $14.1 \%$ (the Netherlands) to $24.6 \%$ (Belgium), while the proportion of patients with more than one hospitalization ranged from $0.6 \%$ (the Netherlands) to $5.4 \%$ (Belgium). The group of patients who received palliative care from their GP spent significantly less time in hospital and had fewer hospitalizations in the last month of life.

The original studies presenting these quality indicators [1,9-11] also specified a performance standard. For the indicator concerning the time spent in hospital in the last month of life, none of the four countries met the performance standard (i.e. less than $10 \%$ of time should be spent in hospital) in our study. One could argue that we did not evaluate the performance of home palliative care, as was the case in the original study in Italy [9] and therefore cannot apply this this performance standard to our data, because while patients were living at home in our study, they were not necessarily receiving home palliative care. Nevertheless, even when we calculated the quality indicator scores for the patients who received palliative care from their GP, only the Netherlands (7.5\%) met this performance standard. This could raise the question of whether a new performance standard needs to be defined when measuring this quality indicator nationwide. In this case, an alternative could be to apply the "best-practice norm" principle: take the bestscoring country's score as the target other countries should aim for in the future.

For the other indicator, concerning the percentage of cancer patients who were hospitalized more than once in the last month of life, the performance standard (i.e. less than $4 \%$ of cancer patients should have more than

Table 2 Quality indicator scores per country and comparing cancer patients who received palliative care from their GP and those who did not

\begin{tabular}{|c|c|c|c|c|c|c|c|c|}
\hline \multirow{3}{*}{ Performance Standard ${ }^{*,+}$} & \multicolumn{4}{|c|}{$\begin{array}{l}\text { "Percentage of time spent in hospital" } \\
\text { in the last month of life (\%) }\end{array}$} & \multicolumn{4}{|c|}{$\begin{array}{l}\text { "Proportion with more than one hospitalization } \\
\text { in the last } 30 \text { days of life" (\%) }\end{array}$} \\
\hline & \multicolumn{4}{|l|}{$<10 \%$} & \multicolumn{4}{|l|}{$<4 \%$} \\
\hline & Belgium & The Netherlands & Italy & Spain & Belgium & The Netherlands & Italy & Spain \\
\hline Total population per country ${ }^{\ddagger}$ & 24.6 & 14.1 & 22.2 & 17.7 & 5.4 & 0.6 & 3.1 & 4.0 \\
\hline Did not receive palliative care from the $G \mathrm{P}^{\S}$ & $39.7 \|$ & $34.7^{\prime \prime}$ & $29.3^{\|}$ & $32.3^{11}$ & 8.3 & 1.3 & $5.1^{\pi}$ & 8.1 \\
\hline Received palliative carefrom the GP\$ & $16.1^{11}$ & $7.5^{11}$ & $18.7 \|$ & $11.8^{\| 1}$ & 4.2 & 0.4 & $2.1^{\pi}$ & 3.3 \\
\hline
\end{tabular}

*Performance standard for the quality indicator "the percentage of time spent in hospital" in the last month of life is 10\% [9].

"Performance standard for the for the quality indicator "the percentage of patients who had more than 1 hospitalization in the last month of life" is $4 \%$ [1,10,11].

${ }^{\ddagger}$ These percentages are standardized for gender, age and cancer type.

${ }^{\S}$ These percentages are not standardized for gender, age and cancer type, since these characteristics did not differ significantly between the two groups in each country.

"Mann Whitney $U$ test showed significant difference, $\mathrm{p}<0.001$.

"Fisher's Exact test showed significant difference, $\mathrm{p}<0.05$. 
one hospitalization in the last month of life) was not achieved in two of the four countries in our study (i.e. Spain and Belgium, with $4.0 \%$ and $5.4 \%$ of patients respectively having more than one hospitalization in the last month). This suggests this performance standard is a feasible goal and can be used as such in the future. The performance standard could even be updated following repeated measurements of these quality indicators, resulting in continuous quality improvement [10].

The between-country differences in quality indicator scores found in this study may reflect differences between these countries in the organization of palliative care. One of these differences may be the role of the GP in the provision of health care in general, and especially in the provision of palliative care. The high degree of responsibility assigned to GPs in the Netherlands, both as general gatekeepers [14] and specifically in the delivery of palliative care $[16,17]$, could be a reason for the fact that hospitalizations in the Netherlands are shorter and rehospitalizations are less frequent. Spain and Belgium have comparable rates, suggesting that the general gatekeeper function of the GP in Spain [14] may not have as much effect on hospitalizations as the fact that the organization of palliative care is the shared responsibility of both GPs and palliative home-care teams [27]. The latter is also the case in Belgium [15]. Despite the fact that in Italy palliative home care is mainly provided by multidisciplinary home teams $[18,19]$, the percentage of time spent in hospital in Italy is relatively high: $22.2 \%$. Another study following an Italian cohort and US cohort in the year after the diagnosis of cancer revealed that the number of hospital admissions was the same in both countries but the mean number of days spent in hospital in Italy was double that of the US cohort [13]. Two potential causes were suggested: the fact that in Italy patients also stay in hospital for e.g. pre-intervention diagnostic tests, whereas in the US these tests were performed in an out-patient setting; and the fact that hospice programs in the US are more established than in Italy, possibly resulting in a higher number of hospitalizations for end-of-life care in Italy [13].

This is in line with the important finding of this study that among the group of patients where the GP provided palliative care, less time was spent in hospital in the last month of life, and multiple hospitalizations were less frequent. We cannot provide insight into the causality in this association due to the design of the study. It might be that patients could stay at home because they insisted on staying at home, had an informal caregiver at home, or had a low symptom burden, and therefore were in the right place to get palliative care from their GP. Nevertheless, this finding highlights the importance of the GP in the organization of palliative care, and the challenge for the GP and home-care services to reduce the number of potentially avoidable hospitalizations.

\section{Strengths and limitations}

This is the first cross-national study using existing data to compare the length and number of hospitalizations in the last month of life, and to assess their function as quality indicators. A strength of the study is that it seems feasible to calculate the scores of these two quality indicators based on data gathered by GPs, as GPs knew where the patient was residing in the last 30 days of life in $96 \%$ of the non-sudden cancer deaths. Consequently, existing GP networks are a feasible candidate for a continuous monitor of some aspects of the quality of palliative care. Nevertheless, there are limitations when using GP networks to collect data. We cannot fully exclude the inaccurate judgment by GPs of patient deaths as being sudden and unexpected.

There may be a bias as GPs may not have been informed or aware of all transfers of the patient to and from hospital or they missed some transitions in the course of recording the data. Due to the anonymous coding of the data collected in the GP networks, we could not validate this information with hospital registries or insurance data. To minimize recall bias, GPs reported on a weekly basis.

Furthermore we do not have information on the reason for hospitalizations in the last month, because we used data recorded by existing GP networks, which did not contain information on this subject. For the same reason, we cannot provide information about whether these hospitalizations were elective or via the emergency department, nor whether they were potentially avoidable or unavoidable. In addition, the availability of hospices and palliative care units might influence whether patients are hospitalized or not in the last month of life. The existing registrations used in this study did not provide any data on the availability of hospices and palliative care units and whether patients with uncontrolled symptoms may have no choice but to be hospitalized. Further research could examine these issues more indepth.

Another limitation is that GPs themselves stated whether they had provided palliative care and we could not examine the validity of this self-reported palliative care provision. We have no detailed information on what GPs considered as "providing palliative care" and were therefore unable to verify whether these definitions were consistent with existing expert definitions. Some GPs may consider care for patients with chronic diseases as palliative care, whereas other consider this as regular GP care. Therefore this study reflects the delivery of what GPs themselves perceive to be palliative care. However, as our study is limited to deceased cancer patients, inter- 
doctor variation is less likely than would be the case in a study of all deceased patients.

\section{Conclusion}

"The percentage of time spent in hospital" in the last month of life and "the proportion with more than one hospitalization in the last 30 days of life" are quality indicators that can be collected with the use of existing sentinel networks of GPs. Quality indicator scores reveal substantial differences between countries, reflecting country-specific differences in the organization of palliative care. In the group of patients who received palliative care from their GP, there were fewer hospitalizations and significantly less time was spent in hospital in the last month, highlighting the important role of the GP in palliative care provision.

\section{Competing interests}

The authors declare that they have no competing interests.

\section{Authors' contributions}

MLDR analyzed the data and drafted the manuscript. ALF and LD supervised MLDR during this process. GM participated in the data analysis. LVDB, GM, BDOP and LD conceived of and designed the study. GAD and AS participated in the data collection. All authors read, critically appraised and approved the final manuscript.

\section{Authors' information}

EURO IMPACT collaborators: Van den Block Lieve, De Groote Zeger, Brearley Sarah, Caraceni Augusto, Cohen Joachim, Francke Anneke, Harding Richard, Higginson Irene J, Kaasa Stein, Linden Karen, Miccinesi Guido, Onwuteaka-Philipsen Bregje, Pardon Koen, Pasman Roeline, Pautex Sophie, Payne Sheila, Deliens Luc.

\section{Acknowledgements}

EURO IMPACT, European Intersectorial and Multidisciplinary Palliative Care Research Training, aims to develop a multidisciplinary, multi-professional and inter-sectorial educational and research training framework for palliative care research in Europe. EURO IMPACT is coordinated by Prof Luc Deliens and Prof Lieve Van den Block of the End-of-Life Care Research Group, Ghent University \& Vrije Universiteit Brussel, Brussels, Belgium.

Collaborators and their affiliations are as follows: Van den Block Lieve, ${ }^{\text {a }}$ De Groote Zeger, ${ }^{a}$ Brearley Sarah, ${ }^{e}$ Caraceni Augusto, ${ }^{g, h}$ Cohen Joachim, ${ }^{a}$ Francke Anneke, ${ }^{b}$ Harding Richard, ${ }^{c, d}$ Higginson Irene ${ }^{j, c, d}$, Kaasa Stein, ${ }^{f}$ Linden Karen, ${ }^{k}$ Miccinesi Guido, Onwuteaka-Philipsen Bregje, ${ }^{\text {b }}$ Pardon Koen, ${ }^{a}$ Pasman Roeline, ${ }^{b}$ Pautex Sophie, Payne Sheila, ${ }^{e}$ Deliens Luc ${ }^{a, b}$. Affiliations: End-of-Life Care Research Group, Ghent University \& Vrije Universiteit Brussel, Brussels, Belgium; ${ }^{a}$ VU University Medical Center, EMGO Institute for health and care research, Amsterdam, the Netherlands; ${ }^{b}$ King's College London, Cicely Saunders Institute, London, ${ }^{c}$ Cicely Saunders International, London, ${ }^{\mathrm{d}}$ and International Observatory on End-of-Life Care, Lancaster University, Lancaster, United Kingdom; ${ }^{e}$ Norwegian University of Science and Technology, and EAPC Research Network, ${ }^{9}$ Trondheim, Norway; Fondazione IRCCS Istituto Nazionale dei Tumori, Milan, Italy, ${ }^{\text {h }}$ and Cancer Research and Prevention Institute, Florence, Italy;i EUGMS European Union Geriatric Medicine Society, Geneva, Switzerland; Springer Science and Business Media, Houten, the Netherlands ${ }^{k}$.

\section{Financial disclosure}

Funding for the study came from the Institute for the Promotion of Innovation by Science and Technology in Flanders as a Strategic Basic Research project (SBO) (contract SBO IWT 050158) (2006-2010), as part of the 'Monitoring Quality of End-of-Life Care (MELC) Study', a collaboration between the Vrije Universiteit Brussel, Ghent University, Antwerp University, the Scientific Institute for Public Health, Belgium, and VU University Medical Centre Amsterdam, the Netherlands. Funding also came from the Italian Ministry of Health through the 'Evaluation, testing and implementation of supportive care, care interventions, integrated programs and improving the quality of care for cancer patients' program ('Integrated Oncology Project $n^{\circ} 6$, years 2008-2011') led by Massimo Costantini (IRCCS AOU San Martino-IST, Genoa), from the annual budgets of the Autonomous Community of Castilla $y$ León and Comunitat Valenciana and from EUROIMPACT: European Intersectorial and Multidisciplinary Palliative Care Research Training, funded by the European Union Seventh Framework Programme (FP7/2007-2013, under grant agreement $n^{\circ}$ [264697]). The funders had no role in study design, data collection and analysis, decision to publish, or preparation of the manuscript.

\section{Author details}

${ }^{1}$ VU University Medical Center, EMGO Institute for Health and Care Research, Department of Public and Occupational Health, Expertise Center of Palliative Care, Van der Boechorststraat 7, 1081 BT Amsterdam, the Netherlands. ${ }^{2}$ NIVEL, Netherlands Institute for Health Services Research, P.O. Box 1568, 3500 BN Utrecht, the Netherlands. ${ }^{3}$ Vrije Universiteit Brussel (VUB), End-of-life Care Research Group Vrije Universiteit Brussel (VUB) and Ghent University, Laarbeeklaan 103, 1090 Brussels, Belgium. ${ }^{4}$ Public Health Directorate General, Regional Ministry of Health, Government of Castilla y León, Paseo de Zorrilla 1, 47071 Valladolid, Spain. ${ }^{5}$ Clinical and Descriptive Epidemiology Unit, Cancer Prevention and Research Institute, ISPO, via Oblate 2, Pal 28/A, 50141 Florence, Italy. ${ }^{6}$ Scientific Institute of Public Health, Public Health and Surveillance, Health Services Research, Juliette Wytsmanstraat 14, 1050 Brussels, Belgium. ${ }^{7}$ Italian Society of General Practioners (SIMG), Via del Pignoncino 9-11, 50142 Florence, Italy.

Received: 21 July 2014 Accepted: 13 November 2014 Published: 27 November 2014

\section{References}

1. Earle CC, Park ER, Lai B, Weeks JC, Ayanian JZ, Block S: Identifying potential indicators of the quality of end-of-life cancer care from administrative data. J Clin Oncol 2003, 21:1133-1138.

2. Mezey M, Dubler NN, Mitty E, Brody AA: What impact do setting and transitions have on the quality of life at the end of life and the quality of the dying process? Gerontologist 2002, 42(Spec No 3):54-67.

3. Earle CC, Landrum MB, Souza JM, Neville BA, Weeks JC, Ayanian JZ: Aggressiveness of cancer care near the end of life: is it a quality-of-care issue? J Clin Oncol 2008, 26:3860-3866.

4. Van den Block L, Deschepper R, Drieskens K, Bauwens S, Bilsen J, Bossuyt N, Deliens L: Hospitalisations at the end of life: using a sentinel surveillance network to study hospital use and associated patient, disease and healthcare factors. BMC Health Serv Res 2007, 7:69.

5. Abarshi E, Echteld M, Van den Block L, Donker G, Deliens L, OnwuteakaPhilipsen B: Transitions between care settings at the end of life in the Netherlands: results from a nationwide study. Palliat Med 2010, 24:166-174.

6. Gott M, Frey R, Robinson J, Boyd M, O'Callaghan A, Richards N, Snow B: The nature of, and reasons for, 'inappropriate' hospitalisations among patients with palliative care needs: A qualitative exploration of the views of generalist palliative care providers. Palliat Med 2013, 27:747-756.

7. Hjermstad MJ, Kolflaath J, Lokken AO, Hanssen SB, Normann AP, Aass N: Are emergency admissions in palliative cancer care always necessary? Results from a descriptive study. BMJ Open 2013, 3:e002515.

8. Barbera L, Paszat L, Qiu F: End-of-life care in lung cancer patients in Ontario: aggressiveness of care in the population and a description of hospital admissions. J Pain Symptom Manage 2008, 35:267-274.

9. Peruselli C, Marinari M, Brivio B, Castagnini G, Cavana M, Centrone G, Magni C, Merlini M, Scaccabarozzi GL, Paci E: Evaluating a home palliative care service: development of indicators for a continuous quality improvement program. J Palliat Care 1997, 13:34-42.

10. Earle CC, Neville BA, Landrum MB, Souza JM, Weeks JC, Block SD, Grunfeld E, Ayanian JZ: Evaluating claims-based indicators of the intensity of end-of-life cancer care. Int J Qual Health Care 2005, 17:505-509.

11. National Quality Forum: National Voluntary Consensus Standards for Symptom Management and End-of-Life Care in Cancer Patients. Washington DC: National Quality Forum; 2006.

12. De Roo ML, Leemans K, Claessen SJJ, Cohen J, Pasman HR, Deliens L, Francke AL: Quality indicators for palliative care: update of a systematic review. J Pain Symptom Manage 2013, 46:556-572.

13. Gigli A, Warren JL, Yabroff KR, Francisci S, Stedman M, Guzzinati S, Giusti F Miccinesi G, Crocetti E, Angiolini C, Mariotto A: Initial treatment for newly 
diagnosed elderly colorectal cancer patients: patterns of care in Italy and the United States. J Natl Cancer Inst Monogr 2013, 2013:88-98.

14. Van den Block L, Onwuteaka-Philipsen B, Meeussen K, Donker G, Giusti F, Miccinesi G, Van Casteren V, Alonso T, Zurriaga O, Deliens L: Nationwide continuous monitoring of end-of-life care via representative networks of general practitioners in Europe. BMC Fam Pract 2013, 14:73.

15. Desmedt $\mathrm{M}$, Michel $\mathrm{H}$ : Palliative home care: improving co-operation between the specialist team and the family doctor. Support Care Cancer 2002, 10:343-348.

16. Ministerie van Volksgezondheid WeS: Verankering van Palliatieve Zorg In De Praktijk [Embedding of Palliative Care in Practice]. [http://www. rijksoverheid.nl/documenten-en-publicaties/kamerstukken/2011/01/14/ verankering-van-palliatieve-zorg-in-de-praktijk.html]

17. Council of Europe: Recommendation Rec (2003) 24 of the Committee of Ministers to member states on the organisation of palliative care. [http:// www.coe.int/T/DG3/Health/Source/Rec(2003)24_en.pdf]

18. Sbanotto A, Burnhill R: Palliative care in Italy: the current situation. Support Care Cancer 1998, 6:426-429.

19. Costantini M, Toscani F, Gallucci M, Brunelli C, Miccinesi G, Tamburini M, Paci E, Di Giulio P, Peruselli C, Higginson I, Addington-Hall J: Terminal cancer patients and timing of referral to palliative care: a multicenter prospective cohort study. Italian cooperative research group on palliative medicine. J Pain Symptom Manage 1999, 18:243-252.

20. Abarshi E, Echteld MA, Van den Block L, Donker G, Bossuyt N, Meeussen K, Bilsen J, Onwuteaka-Philipsen B, Deliens L: Use of palliative care services and general practitioner visits at the end of life in The Netherlands and Belgium. J Pain Symptom Manage 2011, 41:436-448.

21. Van den Block L, Van Casteren V, Deschepper R, Bossuyt N, Drieskens K, Bauwens S, Bilsen J, Deliens L: Nationwide monitoring of end-of-life care via the Sentinel Network of General Practitioners in Belgium: the research protocol of the SENTI-MELC study. BMC Palliat Care 2007, 6:6.

22. Meeussen K, Van den Block L, Echteld MA, Boffin N, Bilsen J, Van Casteren V, Abarshi E, Donker G, Onwuteaka-Philipsen B, Deliens L: End-of-life care and circumstances of death in patients dying as a result of cancer in Belgium and the Netherlands: a retrospective comparative study. $J$ Clin Oncol 2011, 29:4327-4334.

23. Vega Alonso AT, Zurriaga Llorens O, Galmes Truyols A, Lozano Alonso JE, Paisan Maestro L, Gil Costa M, Herrero Llorente A, Ramos Aceitero JM: Guide to the principles and methods of health sentinel networks in Spain. Gac Sanit 2006, 20(Suppl 3):52-60.

24. Deckers JGM, Paget WJ, Schellevis FG, Fleming DM: European primary care surveillance networks: their structure and operation. Fam Pract 2006, 23:151-158.

25. Donker GA: Continuous Morbidity Registration Dutch Sentinel General Practice Network 2010. Annual report. [www.nivel.nl/peilstations]

26. Boffin N, Moreels S, Van Casteren V: The Belgian Network of Sentinel General Practices Between 2007 and 2012: A Short Report. Brussels, Belgium: Scientific Institute of Public Health, Brussels, Belgium; 2013.

27. IIS: Atención a Los Cuidados Paliativos: Organización en Las Comunidades Autónomas. Madrid: Instituto de Información Sanitaria - Sistema de Información de Atención Primaria (SIAP) - Ministerio de Sanidad y Politica Social, Gobierno de Espana; 2009.

\section{doi:10.1186/1472-684X-13-54}

Cite this article as: De Roo et al: Hospitalizations of cancer patients in the last month of life: quality indicator scores reveal large variation between four European countries in a mortality follow-back study. BMC Palliative Care 2014 13:54.

\section{Submit your next manuscript to BioMed Central and take full advantage of:}

- Convenient online submission

- Thorough peer review

- No space constraints or color figure charges

- Immediate publication on acceptance

- Inclusion in PubMed, CAS, Scopus and Google Scholar

- Research which is freely available for redistribution

Submit your manuscript at www.biomedcentral.com/submit
C Biomed Central 